OPEN ACCESS

Edited by:

Giovanni Battista Luciani,

University of Verona, Italy

Reviewed by:

Stiljan Hoxha,

University of Verona, Italy

Krittika Joshi

Cohen Children's Medical Center

United States

*Correspondence:

Guangdi Zhai

zhaoguamgdi@21cn.com

Specialty section:

This article was submitted to

Pediatric Cardiology,

a section of the journal

Frontiers in Pediatrics

Received: 02 September 2020

Accepted: 04 May 2021

Published: 18 June 2021

Citation:

Niu J, Zhai G, Zheng A, Zhou J, Jiang $S$ and Ma J (2021) The Effect of

Optimized Ultrafiltration on

Perioperative Pulmonary Function

During Cardiopulmonary Bypass in Infants Under $10 \mathrm{~kg}$.

Front. Pediatr. 9:602034.

doi: 10.3389/fped.2021.602034

\section{The Effect of Optimized Ultrafiltration on Perioperative Pulmonary Function During Cardiopulmonary Bypass in Infants Under 10 kg}

\author{
Jianhong Niu, Guangdi Zhai*, Aibin Zheng, Juanying Zhou, Shengqi Jiang and Jianping Ma
}

Department of Heart, Changzhou Children's Hospital Affiliated to Nantong University, Changzhou, China

Objective: This study aims to investigate the effect of optimized ultrafiltration on perioperative electrolytes, acid-base balance, and pulmonary function during cardiopulmonary bypass (CPB) in infants with low body weight (under $10 \mathrm{~kg}$ ), using traditional balanced ultrafiltration and modified ultrafiltration.

Methods: A total of 30 children who underwent surgical correction for congenital heart disease in Changzhou Children's Hospital between January 2018 and December 2019 were randomly divided into two groups. In the treatment group, ultrafiltration pre-treatment was carried out with blood-containing priming fluid prior to CPB. Balanced ultrafiltration was performed during the operation, and optimized and modified ultrafiltration were conducted before closing and extubation. In the control group, traditional balanced ultrafiltration was used during the operation, and a modified ultrafiltration combination was used before closing and extubation. Indexes such as blood gas analysis and electrolytes were measured perioperatively, and pulmonary function was observed.

Results: No deaths were reported in either group. The ventilator-assisted breathing time was shorter in the treatment group than in the control group $(P<0.05)$. The indexes of the treatment group were closer than those of the control group to the optimal physiological values. The concentrations of potassium ion $\left(\mathrm{K}^{+}\right)$, lactate (Lac), and blood glucose (Glu) decreased, and there was significant difference between the two groups $(P<0.05)$ at the end of CPB. Hemoglobin $(\mathrm{Hb})$ and hematocrit $(\mathrm{HCT})$ in the treatment group increased $(P<0.01)$. Alveolar-arterial differences for oxygen $\left(\mathrm{A}-\mathrm{aDO}_{2}\right)$ and respiratory index $(\mathrm{RI})$ increased significantly in both groups after operation. Children in the treatment group began to recover lung function earlier than children in the control group. Both $\mathrm{A}-\mathrm{aDO}_{2}$ and $\mathrm{Rl}$ were lower in the treatment group than in the control group at each time point after operation $(P<0.05)$.

Conclusion: Optimizing and modifying the traditional ultrafiltration combination method can effectively shorten the ultrafiltration time, reduce the adverse impacts of the ultrafiltration technique, and improve the lung function of infants after operation.

Keywords: optimized ultrafiltration, $10 \mathrm{~kg}$ or less, infants, cardiopulmonary bypass, pulmonary function 


\section{INTRODUCTION}

The amount of priming fluid used in cardiopulmonary bypass (CPB) is significantly higher (with respect to body surface area) in infants than in adults, especially in infants with body weight below $10 \mathrm{~kg}$. Because of infants' low blood volume and the incomplete development of the immune system, vascular endothelial system, lung function, and kidney drainage function, changes in priming fluid composition and the interaction of related factors in the course of CPB have a significant influence on the internal environment of infants, and there is increased likelihood of acute kidney and lung injury (1-3). As such, mitigating these adverse factors for children with a body weight below $10 \mathrm{~kg}$ is very important.

This study used a blood ultrafilter to ultrafiltrate the bloodcontaining priming fluid of infants in the treatment group before $\mathrm{CPB}$ operation, and balanced ultrafiltration was then performed during the operation. Before closing and extubation, optimized and modified ultrafiltration was used. The effects of this were monitored and compared with the effects of traditional intraoperative balanced ultrafiltration and modified ultrafiltration before closing and extubation on the control group, in order to observe any adverse impacts of traditional ultrafiltration on the control group and identify reduction of tissue edema or improved lung function in the treatment group.

\section{MATERIALS AND METHODS}

\section{Explanation of Terms} Ultrafiltration

A pressure-driven membrane separation technology. The aim is to separate macromolecules from small molecules. At a certain pressure, a solvent and a small molecule solute can pass through a special membrane of a particular pore size, while the macromolecular solute cannot pass through; it therefore stays on one side of the membrane and is partially purified.

\section{Traditional Ultrafiltration}

A modified traditional ultrafiltration technique is used at the end of $\mathrm{CPB}$.

\section{Balanced Ultrafiltration}

It is the one performed during $\mathrm{CPB}$, which does not modify circulating volume, rather it is supposed to filter out inflammatory mediators. Please refer to these definitions and to these only.

\section{Modified Ultrafiltration}

Created by Naik. It is the one performed in the OR at the end of $\mathrm{CPB}$, using the very same cannulae in place for surgery. In this process, the inlet end of the ultrafilter is connected with the arterial segment close to the aortic intubation position by a shape tee, the outlet end is connected with the venous return pipeline, and the blood is reinjected into the right atrium. Modified ultrafiltration can be performed during and after $\mathrm{CPB}$.

\section{Optimized Ultrafiltration}

The combination of three ultrafiltration methods, including preoperative ultrafiltration pretreatment, intraoperative balanced ultrafiltration and modified ultrafiltration before extubation. In this study, the ultrafiltration technology was optimized before the start of $\mathrm{CPB}$, during $\mathrm{CPB}$, and at the end of $\mathrm{CPB}$. On the basis of the optimized ultrafiltration device, a perfusion tube with a diameter of $2 \mathrm{~mm}$ was used to connect the right atrium with the ultrafilter. About $70 \mathrm{ml}$ blood in the vena cava pipeline was recovered and the original vena cava circuit was blocked. (Figure 1B, modified on the basis of the original modified ultrafiltration Figure 1A).

\section{Clinical Data and Grouping}

A total of 30 children (body weight $\leq 10 \mathrm{~kg}$ ) with congenital heart disease treated in Changzhou Children's Hospital between January 2018 and December 2019 were enrolled in the study. A prospective randomized controlled trial was adopted. The first eligible child was divided into treatment group 1, then the second was control group 1; the third was treatment group 2, the fourth was control group 2 , and so on. They were divided into a treatment group $(\mathrm{n}=15)$ and a control group $(n=15)$.

In the experimental group, 15 children with congenital heart disease were pretreated with ultrafiltration before CPB, balanced ultrafiltration was performed during operation and modified ultrafiltration was performed before extubation (Optimized ultrafiltration); in the control group, 15 children with congenital heart disease were treated with zero balanced ultrafiltration during operation and modified ultrafiltration before extubation.

The clinical data of the children in the two groups are shown in Table 1. Surgical options were chosen based on the type of disease. These options included repair of a ventricular septal defect (VSD) with patent foramen ovale (PFO), repair of VSD with patent ductus arteriosus (PDA), ligation of ductus arteriosus, repair of atrial septal defect (ASD) with pulmonary stenosis, correction of pulmonary stenosis, and repair of simple atrial and ventricular septal defects. For example, VSD was repaired under cardiopulmonary bypass; ASD was repaired under cardiopulmonary bypass; VSD and PFO were repaired under cardiopulmonary bypass; VSD and PDA were repaired and ligated under cardiopulmonary bypass; ASD with PS was repaired and PS was corrected under cardiopulmonary bypass. The thoracic closed drainage tube is usually placed in the thoracic cavity after the cardiac surgery. According to the amount of postoperative thoracic drainage, it is usually removed after 2 3 days.

The study was approved by both the ethics committee and the parents of the children.

\section{Inclusion Criteria}

Children with congenital heart disease, including those requiring repair of VSD with PFO, repair of VSD with PDA, ligation of ductus arteriosus, repair of ASD with pulmonary artery stenosis, correction of pulmonary artery stenosis, and repair of simple atrial and ventricular septal defects were included. 

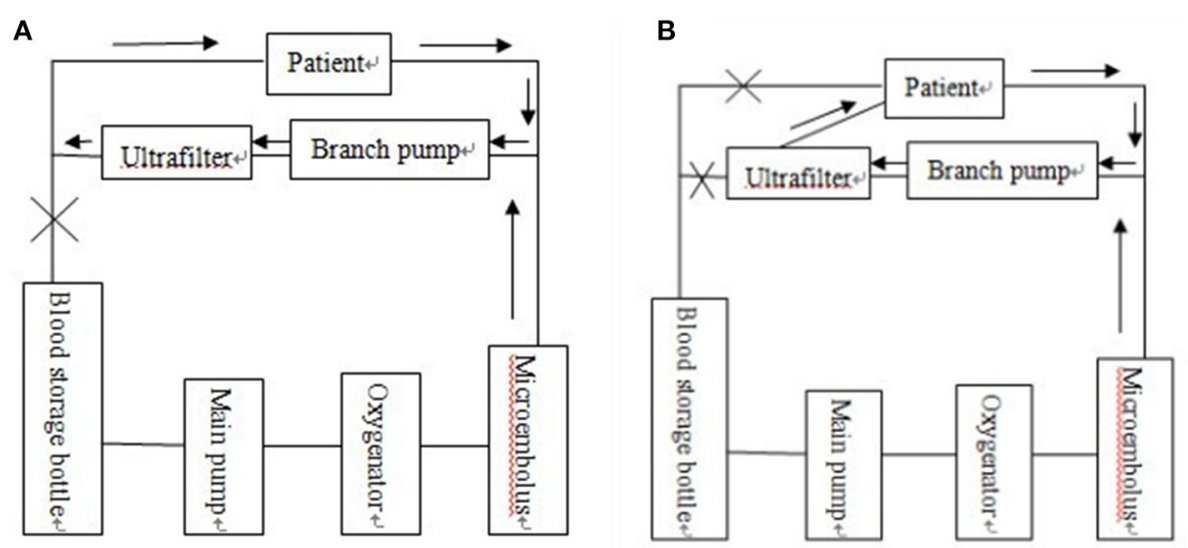

FIGURE 1 | (A) Original traditional modified ultrafiltration tube connection mode diagram. (B) Modern optimized and modified ultrafiltration tube connection mode diagram.

TABLE 1 | General data of Children in both groups $(n=15)$.

\begin{tabular}{lccc}
\hline Clinical data & Treatment group & Control group & $\boldsymbol{P}$ \\
\hline Age $(\mathrm{m})$ & $8.22 \pm 3.23$ & $7.95 \pm 2.90$ & 0.419 \\
Weight(kg) & $8.56 \pm 1.09$ & $8.25 \pm 1.23$ & 0.355 \\
Gender (male/female) & $7 / 8$ & $8 / 7$ & \\
Ventricular septal defect with patent & 5 & 6 \\
foramen ovale & & 0 \\
Ventricular septal defect with patent & 1 & 5 \\
ductus arteriosus & & 3 \\
Ventricular septal defect & 5 & 1 \\
Atrial septal defect & 4 & & \\
Atrial septal defect with pulmonary & 0 & & \\
stenosis & & & \\
& & & \\
\end{tabular}

\section{Exclusion Criteria}

Children with liver and kidney dysfunction, endocrine system diseases, severe pneumonia, heart failure, or coagulation disorders were excluded.

\section{Methods}

\section{Anesthesia and Cardiopulmonary Bypass}

For anesthesia induction, $2 \mathrm{mg} / \mathrm{kg}$ of propofol was used; 20 $\mu \mathrm{g} / \mathrm{kg}$ of fentanyl was used as an analgesic, $0.5 \mathrm{mg} / \mathrm{kg}$ atracurium was used as a muscle relaxant, and $2 \%$ sevoflurane was used for anesthetic maintenance. Before the sternum was split, 10 $\mu \mathrm{g} / \mathrm{kg}$ of fentanyl was also administered. The children were treated with a Stockert C5 artificial heart-lung machine, a Capiox $\mathrm{Rx} 05$ extracorporeal membrane oxygenation and infantile blood ultrafilter, and an extracorporeal supporting tube produced by Ningbo Feilaer Medical Supplies Co., Ltd. The priming fluid was $500 \mathrm{ml}$ of domestic compound electrolyte injection. The arterial microembolus filter outlet was connected to the blood ultrafilter and its outlet connected to the reflux chamber. The flow rate of the ultrafilter was maintained at $300 \mathrm{ml} / \mathrm{min}$ by roller pump.
The optimized and modified ultrafilter had a perfusion tube of about $2 \mathrm{~mm}$ in diameter connecting the right atrium and the ultrafilter so that $\sim 70 \mathrm{ml}$ of blood could be recycled in the vena cava tube and the original vena cava circuit blocked. The schematic diagram is shown in Figure 1.

In the treatment group, after the priming fluid was finished, $300 \mathrm{ml}$ of a suspension containing a small number of white and red blood cells, $20 \mathrm{mg}$ of heparin, and $200 \mathrm{ml}$ of plasma were added. Balanced ultrafiltration was then carried out and $500 \mathrm{ml}$ of compound electrolyte injection was gradually added. Approximately $800 \mathrm{ml}$ of liquid was filtered out over the course of $20 \mathrm{~min}$. The temperature of the water tank was maintained at $38^{\circ} \mathrm{C}$ throughout the procedure and the bank blood was continuously warmed. The ratio of blood flow to ventilation was 1 to 0.5 . Oxygen was added to the bank blood and the carbon dioxide removed.

In the control group, $300 \mathrm{ml}$ of a suspension containing a small number of white and red blood cells, $20 \mathrm{mg}$ of heparin, $200 \mathrm{ml}$ of plasma, and $200 \mathrm{ml}$ of compound electrolyte injection were taken for the priming fluid. Self-circulation was carried out for $20 \mathrm{~min}$ after priming and exhausting.

Both groups were treated with $5 \mathrm{ml} / \mathrm{kg} 5 \%$ sodium bicarbonate, and all children underwent the $\mathrm{CPB}$ operation at room temperature. Myocardial protection was formulated with Del Nido blood-containing cardioplegic solution, with an initial perfusion of $20 \mathrm{ml} / \mathrm{kg}$, followed by $10 \mathrm{ml} / \mathrm{kg}$ after $30 \mathrm{~min}$. All children in the treatment group received the priming fluid for ultrafiltration before the operation, balanced ultrafiltration during the operation, and optimized and modified ultrafiltration after the operation; the children in the control group were treated with balanced ultrafiltration during the operation and with traditional modified ultrafiltration after the operation.

\section{Detection of Blood Gas and Electrolytes During Cardiopulmonary Bypass}

Arterial blood was collected: before $\mathrm{CPB}$ after anesthesia induction, $10 \mathrm{~min}$ after ascending the aorta, $10 \mathrm{~min}$ after the 
TABLE 2 | Comparison of intraoperative and postoperative clinical data between the two groups ( $x \pm s, n=15)$.

\begin{tabular}{lcc}
\hline Clinical data & Treatment group & Control group \\
\hline CPB time (min) & $43.67 \pm 8.77$ & $45.50 \pm 7.24$ \\
Arterial occlusion time (min) & $21.83 \pm 4.76$ & $22.33 \pm 5.69$ \\
Ventilator-assisted breathing time (h) & $7.23 \pm 1.31^{*}$ & $17.45 \pm 5.93$ \\
Chest drainage volume (ml) & $140.58 \pm 52.96$ & $195.41 \pm 73.30$
\end{tabular}

${ }^{\star}$ Comparison between the treatment group and control group $(P<0.05)$.

opening of the aorta, and at the end of $\mathrm{CPB}$. All blood samples were analyzed immediately using a GEM Premier 3,000 blood gas analyzer. The testing indexes included blood $\mathrm{pH}$, partial pressure of oxygen $\left(\mathrm{PaO}_{2}\right)$, partial pressure of carbon dioxide $\left(\mathrm{PaCO}_{2}\right)$, base excess (BE), $\mathrm{Na}+, \mathrm{K}+, \mathrm{Ca}++, \mathrm{Lac}, \mathrm{Glu}, \mathrm{Hb}$, and HCT.

\section{Lung Function Test}

Arterial blood gas, including arterial $\mathrm{PaO}_{2}$ and arterial $\mathrm{PaCO}_{2}$, was measured at $2,6,12,24,48$, and $72 \mathrm{~h}$ after operation. The alveolar-arterial differences for oxygen $\left(\mathrm{A}-\mathrm{aDO}_{2}\right)$ and respiratory index (RI) were calculated using the following formulae:

$$
\begin{aligned}
\mathrm{A}-\mathrm{aDO}_{2}(\mathrm{mmHg}) & =1^{*}(760-47)-\mathrm{PaCO}_{2} / \mathrm{R}-\mathrm{PaO}_{2} \\
\mathrm{RI} & =\mathrm{A}-\mathrm{aDO}_{2} / \mathrm{PaO}_{2} \\
(\mathrm{R} & =0.85) .
\end{aligned}
$$

\section{Statistical Analysis}

SPSS 19.0 software was used for the statistical analysis. The results were expressed by mean \pm standard deviation $(x \pm s)$. The paired or grouped $t$ test was adopted for normal distribution data. The Wilcoxon signed rank-sum test was used for non-normally distributed data. $P<0.05$ was considered statistically significant.

\section{RESULTS}

\section{Clinical Results}

No deaths were reported in either group, and all children were discharged smoothly. The difference in CPB time and aortic occlusion time between the two groups was not statistically significant. The ventilator-assisted breathing time of the children in the treatment group was significantly shorter than that of the control group $(P<0.05)$. The post-operative chest drainage volume was lower in the treatment group than in the control group, but there was no statistical significance. See Table 2 for details of clinical results.

\section{Test Results of Blood Gas and Electrolytes in Children Before and After Cardiopulmonary Bypass}

The differences between the treatment group and control group in $\mathrm{pH}, \mathrm{PaCO}_{2}$, sodium $(\mathrm{Na})$, and calcium $(\mathrm{Ca})$ at each perioperative time point were not statistically significant. The concentrations of $\mathrm{K}^{+}$, Lac, and Glu decreased in the treatment group, and were significantly different at the end of CPB from concentrations in the control group $(P<0.05)$. The $\mathrm{PO}_{2}$ and $\mathrm{BE}$ of the treatment group increased, but the difference compared with the control group was not statistically significant. The $\mathrm{Hb}$ and HCT of the treatment group were significantly higher than those of the control group $(P<0.01)$. See Table 3 for further details of these test results.

\section{Test Results of Pulmonary Function Indexes}

In both groups, both $\mathrm{A}-\mathrm{aDO}_{2}$ and $\mathrm{RI}$ increased significantly after operation. However, levels in the treatment group began to decrease and follow a gradually recovering trend $24 \mathrm{~h}$ after operation, while those in the control group also showed a downward trend, but later: $48 \mathrm{~h}$ after operation. Lung function also tended to recover earlier in the treatment group. At each time point, both $\mathrm{A}-\mathrm{aDO}_{2}$ and $\mathrm{RI}$ were significantly lower in the treatment group than in the control group $(P<0.05)$. See Table 4 for more detail.

\section{DISCUSSION}

In current practice, in order to maintain proper hematocrit during $\mathrm{CPB}$ in infants and young children, a small amount of plasma blood (i.e., red blood cell suspension of low plasma) must be added to the priming fluid. However, the inflammatory mediators and metabolites contained in bank blood, along with low temperature during $\mathrm{CPB}$ and many other factors (e.g., hemodynamic changes or contact between the blood and a foreign body), may have adverse effects on cardiopulmonary function (4-6). At present, traditional intraoperative balanced ultrafiltration and modified ultrafiltration combination technology are widely used in cardiac surgery in China. By eliminating excess water and some inflammatory mediators in the body, hematocrit and colloid osmotic pressure can be improved, thereby improving pulmonary function after operation. However, because the method is implemented only after $\mathrm{CPB}$, it often takes about $15 \mathrm{~min}$ at a flow rate of $10-15 \mathrm{ml} / \mathrm{kg} / \mathrm{min}$ to achieve satisfactory results, prolonging the operation time and increasing the negative impacts of the technique (7). The present study investigated the combined application of priming fluid ultrafiltration before $\mathrm{CPB}$, balanced ultrafiltration during operation, and optimized and modified ultrafiltration before closing and extubation in order to observe the perioperative effects of the method on blood gas, electrolytes, and pulmonary function during $\mathrm{CPB}$.

Some studies have found that a small amount of amount of plasma blood in the bank blood is in a state of low temperature (8), low $\mathrm{pH}$, high $\mathrm{PCO}_{2}$, high $\mathrm{K}^{+}$, and high Glu. Moreover, with prolonged storage time, its cytokines, bradykinin, and other inflammatory mediators increase. The blood in vivo also has contact with non-physiological substances during $\mathrm{CPB}$, resulting in changes to the coagulation system, complement system, and various cytokines; this is one of the causes of post-operative organ dysfunction (9). Moreover, the internal environment of infants and young children, especially of children with body weight below $10 \mathrm{~kg}$, is very fragile: because their organs are imperfectly developed, they experience many post-operative 
TABLE 3 | Test results of blood gas and electrolytes before and after CPB ( $x \pm s, n=15)$.

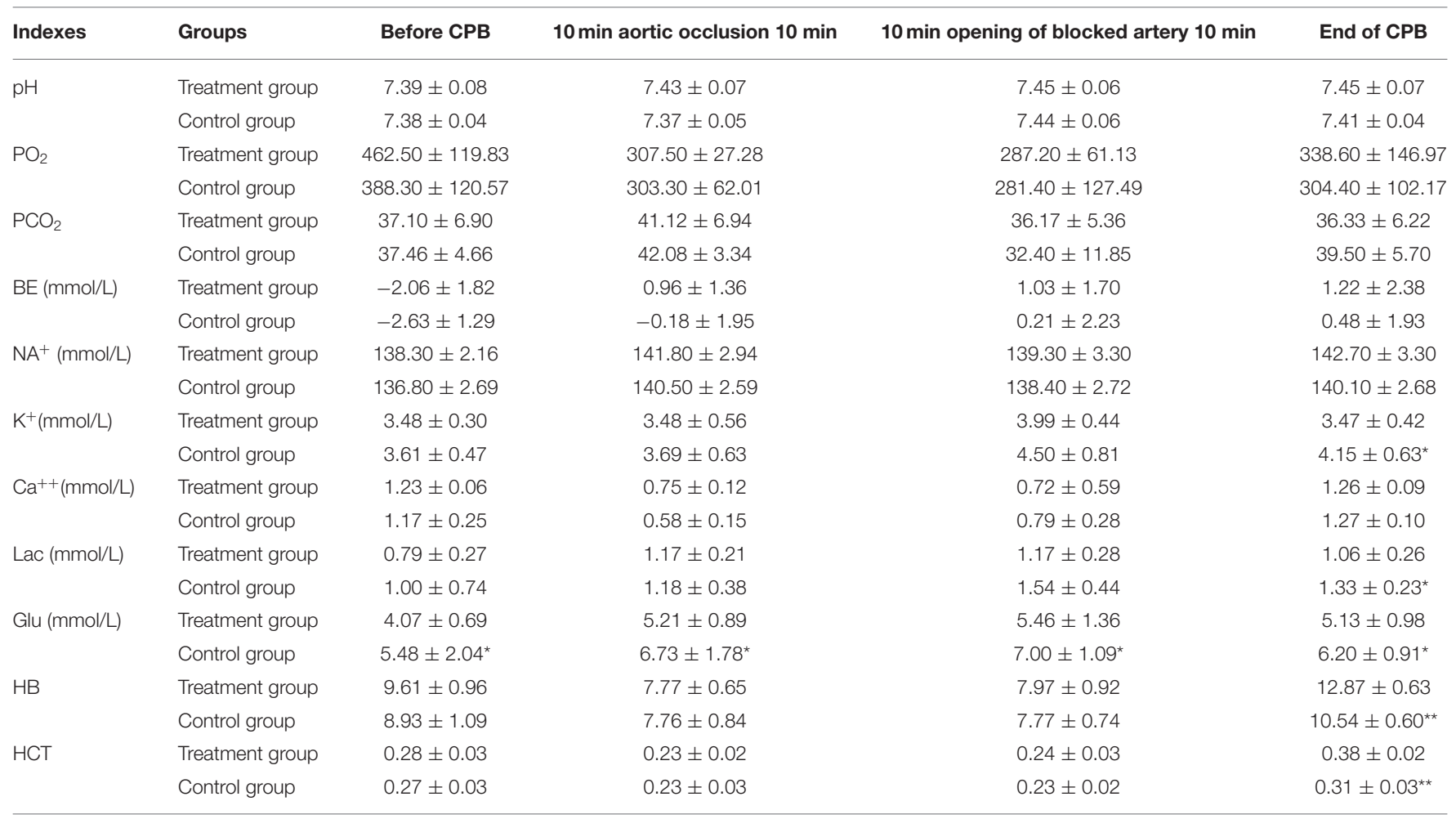

${ }^{*}$ Comparison between the treatment group and control group $(P<0.05)$; ${ }^{* *}$ Comparison between the treatment group and control group $(P<0.01)$.

TABLE 4 | Test results of pulmonary function indexes of children in both groups $(x \pm s, n=15)$.

\begin{tabular}{|c|c|c|c|c|c|c|c|}
\hline Indexes & Groups & \multicolumn{6}{|c|}{ After operation } \\
\hline $\mathrm{A}-\mathrm{aDO}_{2}(\mathrm{mmHg})$ & Control group & $556.28 \pm 20.81^{*}$ & $562.08 \pm 18.49^{\star}$ & $577.33 \pm 11.00^{*}$ & $579.63 \pm 11.71^{*}$ & $581.93 \pm 8.43^{\star}$ & $576.93 \pm 20.43^{*}$ \\
\hline \multirow[t]{2}{*}{$\mathrm{RI}$} & Treatment group & $1.60 \pm 0.49$ & $3.47 \pm 1.19$ & $3.77 \pm 0.69$ & $4.22 \pm 0.96$ & $4.11 \pm 0.75$ & $3.92 \pm 1.01$ \\
\hline & Control group & $5.04 \pm 0.86^{\star}$ & $5.59 \pm 1.02^{*}$ & $6.82 \pm 1.10^{*}$ & $7.08 \pm 1.09^{\star}$ & $7.54 \pm 0.93^{\star}$ & $7.30 \pm 1.59^{\star}$ \\
\hline
\end{tabular}

${ }^{*}$ Comparison between the treatment group and control group $(P<0.05)$.

complications. The present study shows that the ultrafiltration washing of blood-containing priming fluid can effectively reduce the concentration (10) of tumor necrosis factor alpha (TNF-a) and other inflammatory factors, as well as the levels of Glu, Lac, and $\mathrm{K}^{+}$in the priming fluid.

In the treatment group, the internal environment was closer to the optimal physiological values after stopping CPB and performing optimized and modified ultrafiltration. The concentrations of $\mathrm{K}^{+}$, Lac, and Glu decreased in the treatment group, and were significantly different at the end of CPB from concentrations in the control group. The Hb and HCT of the treatment group increased significantly, and were significantly higher than those of the control group.

Previous studies have found that the use of modified ultrafiltration during $\mathrm{CPB}$ in low-weight children can significantly improve perioperative and post-operative pulmonary function (11-14). However, as noted above, because the method is only implemented after CPB it prolongs the operation time and increases the adverse impacts of the technique in children, such as hypothermia, air embolus and thrombosis, hemolysis, hypokalemia, hemodynamic instability, and cerebral ischemia. Optimized and modified ultrafiltration can recover about $70 \mathrm{ml}$ of blood in the vena cava duct, which is equivalent to $25 \%$ of the whole-body blood volume of a child weighing $3.6 \mathrm{~kg}$. The present study demonstrates increased efficiency of ultrafiltration in the treatment group, which means the whole-body blood circulates faster, thereby shortening the ultrafiltration time.

The postoperative chest drainage volume of the two groups: the control group was larger than the experimental group, as shown in Table 2, but there was no statistical significance; Statistics of blood transfusion after operation or before leaving ICU or discharge: in the control group, 3 blood cells, 2 plasma and 2 cryoprecipitated prothrombin complex were transfused. 
On the day after operation and the first day after operation, a total of 3.5 units of blood cells, $200 \mathrm{ml}$ of plasma and 6 cryoprecipitated prothrombin complex were transfused; In the experimental group, 4 blood cells were transfused on the first day after operation, a total of 4.0 units. The time of modified ultrafiltration was $15 \mathrm{~min}$ at the end of operation in both groups. Results the volume of ultrafiltration fluid in the experimental group was significantly larger than that in the control group, with statistical significance. The protocol is the same as the experimental design.

The post-operative $\mathrm{A}-\mathrm{aDO}_{2}$ and $\mathrm{RI}$ of the treatment group at each time point were significantly lower than those of the control group. Furthermore, the lung function of the treatment group tended to recover earlier. The ventilator-assisted breathing time was significantly shorter in the treatment group than in the control group and the post-operative chest drainage volume was lower than that of the control group, which may be related to a decrease in the concentration of inflammatory mediators in the priming fluid of the treatment group.

The decline of pulmonary function after CPB is significantly positively correlated (15) with the neutrophil and IL-8 levels in bronchoalveolar lavage fluid. The results of this study show that the blood injected into the right atrium through the ultrafiltration perfusion tube during the optimized and modified ultrafiltration had high HCT, high colloid osmotic pressure, high coagulation factor, and low inflammatory factor, which can quickly improve the HCT and shorten the time to the optimal oxygen-carrying capacity in the blood after operation, thereby repaying the tissue oxygen debt more quickly and effectively. Therefore, optimized and modified ultrafiltration is important to reduce the negative effects of traditional modified ultrafiltration technology.

\section{CONCLUSION}

The combined perioperative application of priming fluid ultrafiltration, balanced ultrafiltration, and optimized and modified ultrafiltration can bring the internal environment of the body closer to the optimal physiological state during $\mathrm{CPB}$. This is

\section{REFERENCES}

1. Kim-Campbell N, Gretchen C, Callaway C, Felmet K, Kochanek PM, Maul T, et al. Cell-free plasma hemoglobin and male gender are risk factors for acute kidney injury in low risk children undergoing cardiopulmonary bypass. Crit Care Med. (2017) 45:e1123-30. doi: 10.1097/CCM.0000000000002703

2. Shi S, Chen C, Zhao D, Liu X, Cheng B, Wu S, et al. The role of plasma gelsolin in cardiopulmonary bypass induced acute lung injury in infants and young children: a pilot study. BMC Anesthesiol. (2014) 14:67. doi: 10.1186/1471-2253-14-67

3. Liu X, Chen Q, Shi S, Shi Z, Lin R, Tan L, et al. Plasma sRAGE enables prediction of acute lung injury after cardiac surgery in children. Crit Care. (2012) 16:R91. doi: 10.1186/cc11354

4. Bierer J, Stanzel R, Henderson M, Sett S, Horne D. Ultrafiltration in pediatric cardiac surgery review. World J Pediatr Congenit Heart Surg. (2019) 10:77888. doi: $10.1177 / 2150135119870176$

5. Ming ZD, Wei W, Hong C, Wei Z, Xiang DW. Balanced ultrafiltration, modified ultrafiltration, and balanced ultrafiltration with modified expected to effectively shorten the ultrafiltration time from that required by traditional modified ultrafiltration, thus reducing the negative effects of the modified ultrafiltration technology and improving the lung function of infants after operation when $\mathrm{CPB}$ surgery is necessary for low-weight infants with congenital heart disease.

\section{DATA AVAILABILITY STATEMENT}

The original contributions presented in the study are included in the article/supplementary material, further inquiries can be directed to the corresponding author/s.

\section{ETHICS STATEMENT}

The studies involving human participants were reviewed and approved by Ethics Committee of Changzhou Children's Hospital. Written informed consent to participate in this study was provided by the participants' legal guardian/next of kin. Written informed consent was obtained from the individual(s), and minor(s)' legal guardian/next of kin, for the publication of any potentially identifiable images or data included in this article.

\section{AUTHOR CONTRIBUTIONS}

JN and GZ conceived the idea, conceptualized the study, and drafted the manuscript. AZ collected the data. JZ analyzed the data. SJ and JN reviewed the manuscript. All authors read and approved the final draft.

\section{FUNDING}

This study was funded by the major science and technology project of health commission of Changzhou city, Jiangsu province (ZD201717). The funding body had no role in the design of the study and collection, analysis, and interpretation of data and in writing the manuscript. ultrafiltration in pediatric cardiopulmonary bypass. J Extra Corpor Technol. (2001) 33:223-6.

6. Milovanovic V, Bisenic D, Mimic B, Ali B, Cantinotti M, Soldatovic I, et al. Reevaluating the importance of modified ultrafiltration in contemporary pediatric cardiac surgery. J Clin Med. (2018) 7:498. doi: 10.3390/jcm7120498

7. Teng Y, Ding H, Gong Q, Zaishen Jia, Lan Huang. Monitoring cerebral oxygen saturation during cardiopulmonary bypass using near-infrared spectroscopy:the relationships with body temperature and perfusion rate. $J$ Biomed Opt. (2006) 11:16-24. doi: 10.1117/1.2187422

8. Yang J, Yuan Y, Liu J, Song Y, Chen S, Wang J, et al. Banked blood quality and clinical application during different storage periods after ultraviolet irradiation. Chin J Med Phys. (2001) 18:182-8.

9. Jaggers J, Lawson JH. Coagulopathy and inflammation in neonatal heart surgery:mechanisms and strategies. Ann Thorac Surg. (2006) 81:S2360S2366. doi: 10.1016/j.athoracsur.2006.02.072

10. Niu J, Zhai G, Zhang W, Zhang Z, Li J, Zhou J, et al. Effects of priming solution with blood ultrafiltration washing on homeostasis during cardiopulmonary bypass in infants. Jiangsu Med. (2016) 42:38-40. 
11. Hu P, Jiang Z, Xu L, He Z, Sun L, Duan L. Effect of zero-balanced ultrafiltration and modified ultrafiltration on pulmonary function after cardiac surgery in infants. Zhong Nan Da Xue Xue Bao Yi Xue Ban. (2014) 39:698702. doi: $10.11817 /$ j.issn.1672-7347.2014.07.008

12. Boodhwani M, Williams K, Babaev A, Gill G, Saleem N, Rubens FD. Ultrafiltration reduces blood transfusions following cardiac surgcry:a meta-analysis. Eur J Cardiothorac Surg. (2006) 30:892-7. doi: 10.1016/j.ejcts.2006.09.014

13. Ricci Z, PolitoA, NettoR, De Razza F, Favia I, Carotti A, et al. Assessment of modified ultrafil-trationhemodynanmic impact by pressure recording analytical method during pediatric cardian surgery. Pediatr Crit Care Med. (2013) 14:390-5. doi: 10.1097/PCC.0b013e31828 a7113

14. Elliott MJ. Ultrafiltration and modified ultrafiltration in pediatric open heart operations. Ann Thorac Surg. (1993) 56:151822. doi: 10.1016/0003-4975(93)90744-3
15. Kotani N, Hashimoto H, Sessler DI, et al. Neutrophil number and interleukin8 and elastase concentrations in bronchoalveolar lavage fluid correlate with decreased arterial oxygenation after cardiopulmonary bypass. Anesth Analg. (2000) 90:1046-51. doi: 10.1097/00000539-200005000-00009

Conflict of Interest: The authors declare that the research was conducted in the absence of any commercial or financial relationships that could be construed as a potential conflict of interest.

Copyright $\odot 2021 \mathrm{Niu}$, Zhai, Zheng, Zhou, Jiang and Ma. This is an open-access article distributed under the terms of the Creative Commons Attribution License (CC $B Y)$. The use, distribution or reproduction in other forums is permitted, provided the original author(s) and the copyright owner(s) are credited and that the original publication in this journal is cited, in accordance with accepted academic practice. No use, distribution or reproduction is permitted which does not comply with these terms. 